Original Article

\title{
EFFECT OF ETHANOLIC FLOWER EXTRACT OF SPATHODEA CAMPANULATA ON STREPTOZOTOCIN INDUCED DIABETIC NEUROPATHY
}

\author{
RISHIKESH BACHHAV ${ }^{*}$, RAVINDRANATH SAUDAGAR ${ }^{2}$ \\ ${ }^{1}$ Department of Pharmacology, ${ }^{2}$ Department of Pharmaceutical Chemistry, Kalyani Charitable Trust's Ravindra Gambhirrao Sapkal \\ College of Pharmacy, Anjaneri, Trimbakeshwar, Nashik 422213, Maharashtra, India \\ Email: bachhavrss@rediffmail.com
}

Received: 11 Aug 2017 Revised and Accepted: 29 Mar 2018

\begin{abstract}
Objective: To evaluate the effect of ethanolic extract of the flower of Spathodea camapanulata (EFESC) on streptozotocin-induced diabetic neuropathy.

Methods: Non-insulin dependent diabetes mellitus (NIDDM) was induced in overnight fasted adult wistar strain albino male rats weighing 160$200 \mathrm{~g}$ by a single intraperitoneal injection (i. p) of streptozotocin (STZ-65 mg/kg). The rats were randomized into six groups, with six animals each, namely normal control (NC) (Treated with $1 \%$ carboxymethyl cellulose solution), diabetic control (DC) (65 mg/kg., i. p. STZ), test group treated at various doses of EFESC250, EFESC500, and EFESC750, standard control-glibenclamide $0.25 \mathrm{mg} / \mathrm{kg}$ b.w.(SCG) and the treatment has begun from the day of blood sugar level (BSL) detection after the STZ treatment. Body weight was checked daily and serum glucose levels were measured at $48 \mathrm{~h}$, $15^{\text {th }}$ and $28^{\text {th }} \mathrm{d}$ of study. Reaction time to thermal hyperalgesia and cold allodynia were measured after induction of diabetes. In vitro, aldose reductase inhibition assay was carried out.
\end{abstract}

Results: The preliminary phytochemical screening revealed the steroids, terpenoids, coumarins, carbohydrates, tannins, glycosides, and flavonoids in EFESC. DC group showed decreased in reaction time (hyperalgesia) compared to NC while a significant increase in reaction time was observed at various doses EFESC250, EFESC500, EFESC750 and SCG0.25. EFESC at various doses showed the significant reduction in BSL and body weight on $15^{\text {th }}$ and $28^{\text {th }} \mathrm{d}$ in STZ diabetic rat at various dose levels. In vitro, aldose reductase inhibition was observed with an IC 50 at $131 \mu \mathrm{g} / \mathrm{ml}$.

Conclusion: EFESC showed reduced in BSL and prevents hyperalgesia in experimental diabetic neuropathy. It also reduced aldose-reductase level that may play an important role in reducing the complication of diabetic neuropathy.

Keywords: Spathodea campanulata, Neuropathy, Hyperalgesia, Streptozotocin

(c) 2018 The Authors. Published by Innovare Academic Sciences Pvt Ltd. This is an open access article under the CC BY license (http://creativecommons.org/licenses/by/4.0/) DOI: http://dx.doi.org/10.22159/ijpps.2018v10i5.21968

\section{INTRODUCTION}

Diabetes mellitus (DM) is a complex metabolic disorder characterized by hyperglycemia due to defects in insulin secretion, insulin action or both [1]. It affects the metabolism of carbohydrates, proteins and fats in the body. The long-term elevated glucose level in the blood is easy to cause a variety of diabetic complication such as a neuropathy [2], nephropathy [3], cardiopathy [4] and retinopathy [5]. As the prevalence of diabetes has risen to epidemic proportions worldwide, diabetic vascular complications have now become one of the most challenging health problems. Diabetic neuropathy is one of the most common complications of DM. Patients with this neuropathy experience symptoms such as spontaneous pain, allodynia, and hyperalgesia with an incidence rate of $10-20 \%$ [6-8].

Spathodea campanulata (SC) P. Beauv. (Bignoniaceae) is a plant species used in folkloric medicine in Ghana and several African countries. The generic name comes from the Ancient Greek word Spathe, in reference to the spadix-like calyx. In Ghana, it is a locally known medicinal plant used for the treatment of various disorders almost as a universal remedy. The bark has laxative and antiseptic properties, and the seeds, flowers and roots are used as medicines for several conditions $[9,10]$.

SC flowers and bark are used traditionally in the treatment of mental disorders, malaria, haemorrhoids, bacterial infections, HIV, poor blood circulation, gastrointestinal diseases, respiratory ailments, genital-urinary system disorders etc. [11-16]. The flowers of Spathodea camanulata possesses an anti-inflammatory and diuretic property. While its stem bark has anti-malarial, hypoglycemic, anticomplement, and anti-HIV properties [17, 18]. In Ghana decoction of the stem bark of SC exerted a hypoglycemic activity in STZ-induced rats $[12,18]$. The flowers of SC reported that phytoconstituents responsible for its antidiabetic activity $[19,20]$. On the basis phytochemical and pharmacological evaluation the aim and objective of the present study to investigate the effect of EFESC of STZ-induced diabetic neuropathy in rats.

\section{MATERIALS AND METHODS}

\section{Collection of plant material}

The fresh flowers of plant materials of SC were collected from Pawan Nagar, New-Nashik (MS), India, during the mo of October 2014. The plant is authenticated and deposited at the Botanical Survey of India, Pune. A Voucher Specimen (RSB-1) was deposited at the Institute for further reference.

\section{Chemicals, reagents and drugs}

Petroleum ether $\left(60-80^{\circ} \mathrm{C}\right)$, ethanol, (Loba Chemie-Mumbai), streptozotocin (Sigma Aldrich Chemicals) and glibenclamide (Cadila Pharmaceuticals Ltd.) were used as a standard control. Carboxymethylcellulose (CMC-Hi media Pvt. Ltd). All other chemicals, solvents and reagents used were of the highest analytical grade. A standardized EFESC was prepared in 1\% CMC.

\section{Extraction and phytochemical screening}

The flowers of plant material of SC $(2.0 \mathrm{~kg})$ were dried at room temperature. It was ground to coarse powder. The powder materials were defatted three times with $15 \mathrm{l}$ of petroleum ether $\left(60-80^{\circ} \mathrm{C}\right)$ using soxhlet apparatus. The petroleum ether extracts were filtered and the solvent was removed under reduced pressure in a rota evaporator (Buchi Laboratories). The defatted materials were stored at $-20^{\circ} \mathrm{C}$. The defatted plant material of flowers of SC was obtained $0.9 \mathrm{~g}(45 \%)$ further flowers extract of SC extracted with $10 \mathrm{l}$ of $90 \%$ ethanol at room temperature. EFESC concentrated under reduced pressure and dried in a freeze dryer. The practical yield of EFESC 
was $7.0 \mathrm{~g}(35 \% \mathrm{w} / \mathrm{w})$. EFESC was further analyzed by various phytochemical tests for carbohydrates, proteins, amino acids, saponins glycosides, alkaloids, flavonoids, steroids, tannins and triterpenoids [21-23].

\section{Animals}

The study was carried out after the approval of the Institutional Animal Ethics Committee (Reg No. 1542/po/a/CPCSEA/2008). Adult male wistar albino rats, aged 10-12 w, weighing 160-200 g were obtained from Lacsmi Biofarm (Reg. No. 1277/CPCSEA/2000). They were acclimatised to room temperature with a relative humidity $55 \pm 10 \%$ for $2 \mathrm{w}$ during which time they were provided a standard feed (Amrut Feed) and filtered water ad libitum. They were housed in propylene cages.

\section{Acute toxicity study}

Acute toxicity assay was performed as per OECD guidelines 423(limit test). Six female wistar albino rats (three animals in each step) were randomly selected. The animals were kept fasting for overnight providing only water. The test drug was administered orally at one dose level of $2000 \mathrm{mg} / \mathrm{kg}$ b.w. The rats were observed continuously for the first $4 \mathrm{~h}$ and then periodically up to $24 \mathrm{~h}$ for toxic symptoms and mortality.

\section{Experimental design}

Induction of non-insulin dependent diabetes mellitus (NIDDM)

NIDDM was induced in overnight fasted adult wistar albino male rats weighing 160-200 g by a single intraperitoneal injection of 65 $\mathrm{mg} / \mathrm{kg}$ streptozotocin (Sigma Aldrich, Germany). STZ was dissolved in citrate buffer ( $\mathrm{pH} 4.5)$ as per international models of diabetes complications donsortium. Within $72 \mathrm{~h}$ following STZ administration, blood glucose concentration was estimated by enzymatic GOD-POD (Glucose-oxidase-peroxidase) diagnostic kit method (Accurex). The rats with fasting blood sugar (FBS) more than $200 \mathrm{mg} / \mathrm{dl}$ means hyperglycemia was confirmed by the elevated glucose levels in plasma. The rats found with permanent NIDDM were used for the antidiabetic study. The EFESC was prepared in 1\% CMC solution and given orally (p. o.) for the treatment group. Standard controlglibenclamide- 0.25 (SCG-0.25) dissolved in $0.9 \%$ sodium chloride administered intraperitoneally. The rats were randomized into six groups, with a minimum of six animals each, and the treatment began from the day of blood sugar level (BSL) detection after the STZ treatment. Body weight was checked daily and serum glucose levels were measured after $48 \mathrm{~h}, 15^{\text {th }} \mathrm{d}$ and $28^{\text {th }} \mathrm{d}$ of study [24-25]

The animals were divided as per following groups,

I-normal control (NC) (Treated with $1 \%$ CMC solution)

II-diabetic control-(DC)-(65 mg/kg., i. p. STZ)

III-EFESC $250 \mathrm{mg} / \mathrm{kg}$, (p. o.)

IV-EFESC $500 \mathrm{mg} / \mathrm{kg}$, (p. o.)

V-EFESC $750 \mathrm{mg} / \mathrm{kg}$ (p. o.)

VI-SCG-0.25 mg/kg b.w. (i. p)

\section{Assesment of thermal hyperalgesia and cold allodynia}

\section{Tail immersion (warm water) test}

The tail of rat was immersed in a warm water $\left(47 \pm 1^{\circ} \mathrm{C}\right)$ bath until tail withdrawal (flicking response) or signs of struggle were observed (cutoff 15s). Shortening of tail-withdrawal indicates hyperalgesia.

\section{Tail immersion (cold water) test}

The procedure is same as a warm water test but the temperature of the water was set at $10 \pm 0.5{ }^{\circ} \mathrm{C}$, a temperature that is normally innocuous. The cut-off time was $15 \mathrm{~s}$. the shorten duration of tail immersion indicates allodynia.

\section{Hotplate test}

In this test, animals were placed individually on a hot plate (Inco Digital) with temperature adjusted to $55 \pm 1{ }^{\circ} \mathrm{C}$. The latency to the first sign of paw licking or jump response to avoid heat pain was taken as an index of pain threshold. The cut-off time was kept $10 \mathrm{~s}$ so as to avoid damage to the paw. Both hyperalgesia and allodynia were assessed weekly till the end of the study [26-28].

\section{In vitro aldose reductase inhibition assay}

For the determination of the aldose reductase inhibitory activity of the different concentration of EFESC was selected, The incubation mixture, in a final volume of $250 \mu \mathrm{l}$, consisted of $67 \mathrm{mmol}$ potassium phosphate buffer (pH-6.2), 0.4 M lithium sulphate, $150 \mu \mathrm{M} \mathrm{NADPH,}$ $300 \mu \mathrm{M}$ DL-glyceraldehyde, enzyme $(50 \mu \mathrm{l})$. Quercetin $0.5 \mu \mathrm{g} / \mathrm{ml}$ was used as standard inhibitor. Appropriate blanks were prepared for quercetin and the test samples without DL glyceraldehyde. The reaction was initiated by adding NADPH. The absorbance was read at $340 \mathrm{~nm}$ for $20 \mathrm{~min}$ using microplate reader (BMG Labtech) in a kinetic mode. The percent inhibition by test sample/quercetin was calculated by considering the control value as $100 \%$, using the equation mentioned below. The median inhibitory concentration $\left(\mathrm{IC}_{50}\right)$ was calculated using Finney software. A similar procedure was carried out with EEFSC at strengths of 5, 10, 25, 50, 100 and 200 $\mu \mathrm{g} / \mathrm{ml}$ [29]. The percentage inhibition was calculated with the following formula:

$$
100-\frac{(\Delta A 340 \text { samplex } 100)}{\Delta A 340 \text { control }}
$$

Where. $\Delta$ A340 = changes in absorance at $340 \mathrm{~nm}$

\section{Statistical analysis}

Data were expressed as mean \pm SEM of the animal in each group. To determine statistical significance, ANOVA followed by Dunnett's test was used for post hoc analysis. $\mathrm{P}<0.05$ was considered as statistically significant. IC 50 was calculated for the in vitro aldose inhibitory activity of EFESC.

\section{RESULTS}

Preliminary phytochemical screening of Spathodea campanulata

The petroleum ether extract of the flower of SC showed the presence of saponins, terpenoids, steroids, quinones, coumarins and proteins. The EFESC showed presence of flavonoids, saponins, terpenoids, proteins, carbohydrates, coumarins, quinones, glycosides and phenolic compounds.

\section{Acute toxicity of EFESC}

The acute oral toxicity study was carried out according to OECD guidelines No.423. The tested extract did not exhibit any toxicity symptoms and mortality in all groups when given orally at a dose $2000 \mathrm{mg} / \mathrm{kg}$ b.w. EFESC were safe up to the dose of $2000 \mathrm{mg} / \mathrm{kg} \mathrm{b.w}$. hence three different doses $(250,500$ and $750 \mathrm{mg} / \mathrm{kg}$ b.w.) were arbitrarily selected for the pharmacological study.

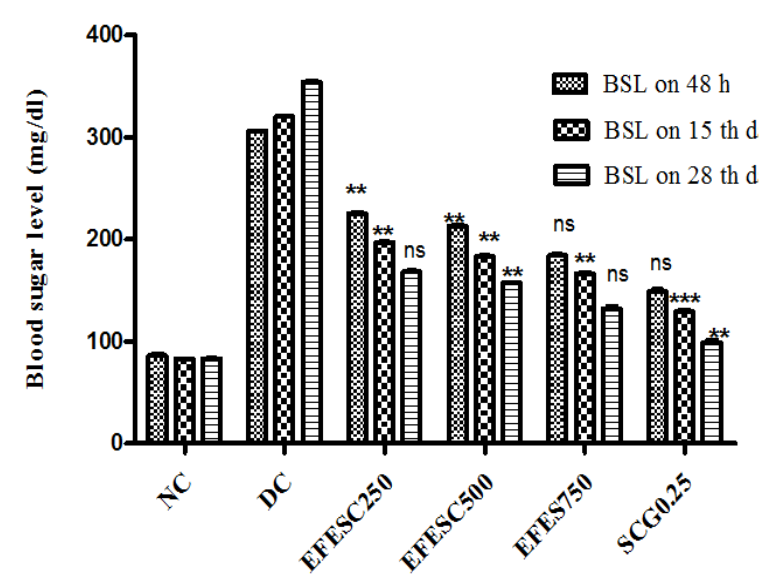

Fig. 1: Effect of EFESC on blood sugar level (BSL) in STZ induced diabetes in rats 


\section{Effect EFESC on blood sugar levels (BSL)}

BSL of the NC group of animals did not alter throughout the experiment. In DC group BSL level increased steadily on $15^{\text {th }} \mathrm{d}$ $(320 \pm 0.67)$ and on $28^{\text {th }} d(354 \pm 1.1)$ after STZ treatment indicating the incidence of diabetes in the animals throughout the experiment (fig. 1). There were significant changes in BSL of SCG0.25 treated animals $(149 \pm 2.00 \mathrm{mg} / \mathrm{dl}) 48 \mathrm{~h}$ post-STZ treatment as compared to DC group of animals $(306 \pm 0.58 \mathrm{mg} / \mathrm{dl})$ indicating the incidence of diabetes. There was a significant reduction in BSL of EFESC on $15^{\text {th }}$ and $28^{\text {th }} \mathrm{d}$ in the STZ-induced diabetic rat at various dose levels.

Each Value represents as mean \pm SEM. $(n=6)$. The comparisons were made by one way ANOVA followed by Dunnett's test. ns=nonsignificant, $\mathrm{STZ}=$ streptozotocin. $\mathrm{NC}=$ normal control, $\mathrm{DC}=$ diabetic control, EFESC=ethanolic flower extract of Spathodea campanulata,
SCG0.25=standard control glibenclamide. ${ }^{*} \mathrm{p}<0.05,{ }^{* *} \mathrm{p}<0.01$ and ${ }^{* * *} \mathrm{p}<0.001$ is considered as significant when compared to the control group.

Effect of EFESC on hyperalgesia produced by tail immersion (hot water) method

There was no change in tail flick latency (s) observed in NC group of the animal throughout the experiment. A gradual decline in the latency was observed in DC group of the animal from day $7^{\text {th }}$ $(8.4 \pm 0.10)$ onward which was observed minimum on day $28^{\text {th }}$

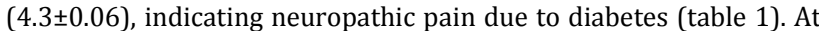
three different doses level of EFESC also showed a significant reduction in latency from $14^{\text {th }} d$ to $28^{\text {th }} \mathrm{d}$ increase in pain threshold time, indicating an absence of algesia produced by tail immersion in hot water.

Table 1: Effect of EFESC on hyperalgesia produced by tail immersion (hot water) in STZ-induced diabetes in rats

\begin{tabular}{|c|c|c|c|c|c|}
\hline \multirow{2}{*}{$\begin{array}{l}\text { Groups } \\
(n=6)\end{array}$} & \multirow[t]{2}{*}{ Treatment } & \multicolumn{4}{|c|}{ Tail flick latency (s) } \\
\hline & & $7^{\text {th }} \mathrm{d}$ & $14^{\text {th }} \mathrm{d}$ & $21^{\text {st }} d$ & $2^{\text {th }} d$ \\
\hline I & NC & $13 \pm 0.07$ & $11 \pm 0.09$ & $12 \pm 0.12$ & $11.0 \pm 0.14$ \\
\hline II & DC & $8.4 \pm 0.1$ & $6.3 \pm 0.0$ & $5.3 \pm 0.06$ & $4.3 \pm 0.06$ \\
\hline III & EFESC250 & $8.6 \pm 0.08$ & $9 \pm 1.00 * *$ & $9.4 \pm 0.03^{* *}$ & $10.0 \pm 0.01^{* *}$ \\
\hline IV & EFESC500 & $9.1 \pm 0.16$ & $9.1 \pm 0.01^{* *}$ & $10 \pm 0.07^{* *}$ & $11.0 \pm 0.02^{* *}$ \\
\hline V & EFESC750 & $9.1 \pm 0.01$ & $9.9 \pm 0.02^{* *}$ & $11 \pm 0.01^{*}$ & $11.0 \pm 0.02 * *$ \\
\hline VI & SCG025 & $9.9 \pm 0.01^{* * *}$ & $10 \pm 0.01^{* * *}$ & $10 \pm 0.03^{* * *}$ & $11.0 \pm 0.05^{* * *}$ \\
\hline
\end{tabular}

The data are expressed as mean \pm SEM. $(n=$ number of animals in each group $=6)$. The comparisons were made by one way ANOVA followed by Dunnett's test. STZ=streptozotocin, NC=normal control, DC=diabetic control, EFESC=ethanolic flower extract of Spathodea campanulata SCG0.25=standard control glibenclamide. ${ }^{*} p<0.05,{ }^{* *} p<0.01$ and ${ }^{* * *} p<0.001$ is considered as significant when compared to the control group.

Effect of EFESC on allodynia produced by tail immersion (cold water) method

No significant change in latency was observed in NC of the animal throughout the study. For DC group of an animal, there was a gradual reduction in latency (s) was observed from day $7^{\text {th }}$
$(10.0 \pm 0.01)$ till $28^{\text {th }} d(4.3 \pm 0.06)$ indicating the presence of allodynia (table 2). In the treatment group of animals i.e. EFESC with increasing dose showed significant $(* * p<0.01)$ increased in latency time $(\mathrm{s})$ at $14^{\text {th }}$ and $28^{\text {th }} \mathrm{d}$ was exhibited which implies the protective action of drug treatment on allodynia produced by cold water.

Table 2: Effect of EFESC on allodynia produced by tail immersion (cold water) in STZ induced diabetes in rats

\begin{tabular}{|c|c|c|c|c|c|}
\hline \multirow{2}{*}{$\begin{array}{l}\text { Groups } \\
(n=6)\end{array}$} & \multirow[t]{2}{*}{ Treatment } & \multicolumn{4}{|c|}{ Tail flick latency (s) } \\
\hline & & $7^{\text {th }} d$ & $14^{\text {th }} d$ & $21^{\text {st }} d$ & $28^{\text {th }} d$ \\
\hline I & $\mathrm{NC}$ & $14.0 \pm 0.12$ & $13.0 \pm 0.07$ & $14.0 \pm 0.04$ & $13.0 \pm 0.09$ \\
\hline II & $\mathrm{DC}$ & $10.0 \pm 0.01$ & $7.3 \pm 0.05$ & $5.4 \pm 0.08$ & $4.3 \pm 0.06$ \\
\hline III & EFESC250 & $12.0 \pm 0.06$ & $12.1 \pm 0.05^{*}$ & $12.7 \pm 0.02^{* *}$ & $13.1 \pm 0.04^{* *}$ \\
\hline IV & EFESC 500 & $13.0 \pm 0.05$ & $12.7 \pm 0.05^{\mathrm{ns}}$ & $13.5 \pm 0.02^{* *}$ & $14.0 \pm 0.04^{* *}$ \\
\hline V & EFESC750 & $13.0 \pm 0.02$ & $12.9 \pm 0.03^{n}$ & $14.0 \pm 0.56^{* *}$ & $14.0 \pm 0.02^{* *}$ \\
\hline VI & SCG0.25 & $13.66 \pm 0.04$ & $13.80 \pm 0.02 *$ & $14.69 \pm 0.03^{* * *}$ & $14.30 \pm 0.03^{* * *}$ \\
\hline
\end{tabular}

The data are expressed as mean \pm SEM. $(\mathrm{n}=$ number of animals in each group $=6$ ). The comparisons were made by one way ANOVA followed by Dunnett's test. ns = non-significant, STZ = streptozotocin. NC =normal control, DC=diabetic control, EFESC=ethanolic flower extract of Spathodea campanulata, SCG0.25=standard control glibemcamide. ${ }^{*} p<0.05,{ }^{* *} p<0.01$ and ${ }^{* * *} \mathrm{p}<0.001$ is considered as significant when compared to the control group.

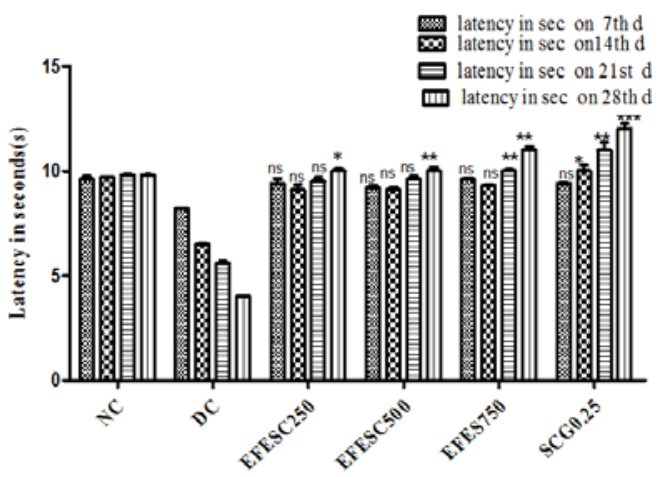

Fig. 2: Effect of EFESC on thermal hyperalgesia (hot plate) in STZ induced diabetes in rats

\section{Effect of EFESC on thermal hyperalgesia by a hot plate method}

No significant change in latency was observed in NC group of animals, throughout the study (fig. 2). For DC group of animals, there was a gradual reduction in latency (s) observed from day $7^{\text {th }} d$ $(8.20 \pm 0.01 \mathrm{~s})$ till $28^{\text {th }} d(4.00 \pm 0.04 \mathrm{~s})$ where the pain was observed to be maximum, indicating the presence of algesia by heat. In the EFESC treated a group of animals, no significant lowering of pain latency was exhibited which implies the protective action of GLB on hyperalgesia produced in diabetic animals.

The data are expressed as mean \pm SEM. ( $\mathrm{n}=$ number of animals in each group $=6$ ). The comparisons were made by one way ANOVA followed by Dunnett's test. ns = non-significant, $\mathrm{STZ}=$ streptozotocin. $\mathrm{NC}=$ normal control, DC=diabetic control, EFESC=ethanolic flower extract of Spathodea campanulata, SCG0.25=standard control glibemclamide. ${ }^{*} \mathrm{p}<0.05,{ }^{* *} \mathrm{p}<0.01$ and 
${ }^{* * *} \mathrm{p}<0.001$ is considered as significant when compared to the control group.

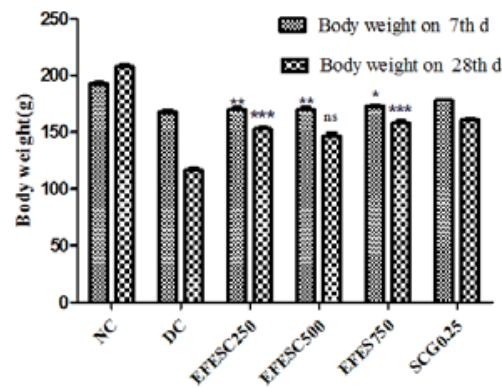

Fig. 3: Effect of EFESC on body weight

\section{Effect of EFESC on body weight}

There was a decrease in body weight in the DC group as compared to NC group which was not statistically significant.
The SCG0.25 group showed significantly increased in weight as compared to DC group (fig. 3). EFESC showed a significant reduction in body weight $(\mathrm{g})$ compared to $\mathrm{NC}$ and $\mathrm{DC}$ value. There was no reduction in feed intake in any of the group.

The data are expressed as mean \pm SEM. $(n=$ number of animals in each group $=6$ ). The comparisons were made by one way ANOVA followed by Dunnett's test. ns $=$ non-significant, STZ = streptozotocin.

$\mathrm{NC}=$ normal Control, DC=diabetic control, EFESC=ethanolic flower extract of Spathodea campanulata, SCG0.25=standard control glibemcamide. ${ }^{*} \mathrm{p}<0.05,{ }^{* *} \mathrm{p}<0.01$ and ${ }^{* * *} \mathrm{p}<0.001$ is considered as significant when compared to the control group.

\section{Effect of EFESC on aldose enzyme reductase activity in vitro}

Quercetin at a concentration of $0.5 \mu \mathrm{g} / \mathrm{ml}$ exhibited $46.19 \%$ inhibition of aldose reductase activity. Percent inhibition of aldose reductase enzyme by the EFESC samples at different concentrations were calculated and plotted on a graph. IC ${ }_{50}$ of EFESC was $131 \mu \mathrm{g} / \mathrm{ml}$ (table 3).

Table 3: Effect of EFESC on aldose enzyme reductase activity in vitro

\begin{tabular}{ll}
\hline Conc. tested $(\boldsymbol{\mu g} / \mathbf{m l})$ & (\% Inhibition) \\
\hline 5 & 5.74 \\
10 & 10.58 \\
25 & 21.23 \\
50 & 36.72 \\
100 & 46.91 \\
200 & 71.52 \\
$\mathrm{IC} 50(\mu \mathrm{g} / \mathrm{ml})$ & 131 \\
\hline
\end{tabular}

\section{DISCUSSION}

Pain associated with nerve damage from diabetes initially involves peripheral mechanisms causing sensory fibres hypersensitivity, which secondarily leads to central rearrangements responsible for central nociceptive system hyperexcitability. In this study the main peripheral and central mechanisms of diabetic neuropathic pain proposed by the work using the STZ-rat model. Peripheral diabetic neuropathy is a devastating complication of diabetes and a leading cause of foot amputation. Diabetic neuropathy is characterized by clinical features like allodynia, hyperalgesia due to elevated nociceptive response, neuronal hypoxia and reduced threshold to painful stimuli [30]. Similar symptoms are exhibited by STZ induced diabetic animals [31]. Hyperglycemia and inflammation unleash a cascade of events that affect cellular proteins, gene expression and cell surface receptor expression, ultimately resulting in progressive pathologic changes and subsequent diabetic complications [32]. The STZ induced diabetic rats are the most commonly employed animal model of painful diabetic neuropathy [33]

The model chosen in the present study was based on the principle that at an increased level of blood sugar in a diabetic rat, hyperalgesia due to the hyperactivity of C-nociceptive fibres will be observed. This can be detected as a reduced latent period (reaction time) for the tail flick in response to radiant heat by the analgesiometer [34]. EFESC would beneficial in DN will reverse the hyperalgesia.

The mechanisms of cold allodynia and hyperalgesia include peripheral and central sensitization, or central disinhibition, such as sensitization of $\mathrm{C}$ nociceptors or $\mathrm{A} \delta$ fibres. Microneurographic recordings in a patient with small-fibre neuropathy and cold allodynia showed sensitization to cold and menthol responsiveness of subtypes of $\mathrm{C}$ nociceptors [35]. Blockade of $\mathrm{A} \delta$ fibres during nerve compression [36,37]or disease[38] causes an increase in cold detection thresholds, a decrease in cold pain thresholds, and a change in the quality of cold sensation to icy, stinging, hot, and burning sensations. This is thought to result from disinhibition of Cpolymodal nociceptive fibres (heat-pinch-cold fibres) by the loss of
A $\delta$ fibres [39] and could provide an explanation for cold allodynia in neuropathic pain patients.

Phytochemical studies were performed with different parts of SC, including stem barks, leaves, flowers and fruits. Spathodic acid, steroids, saponins, ursoilc acid, tomentosolic acid and phenolic substance were isolated from stem bark. The flowers showed the presence of anthocyanins, while the floral nectar contains the complex mixture of triterpenoids and steroids [40-41].

The studied EFESC are rich in flavonoids, steroids and anthraquinones like compound. The EFESC extract probably contains quercetin type of flavonoids like phytoconstituents. The effect of quercetin in DN could be mediated possibly through a peripheral mechanism. One of the possible mechanisms that could partially explain the beneficial analgesic property of quercetin may be attributed to its hypoglycemic and antioxidant effects. Since hyperglycemia in the diabetic state could induce some functional alterations in the nervous system [42], quercetin may have attenuated the hyperalgesia in diabetic rats through lowering blood glucose that may be the probable mechanism for the present study. The SC plant is also reported for its analgesic and anti-inflammatory activity. These phytoconstituent are a positive modulator for neuropathic pain and their antinociceptive effect.

The studied plant of SC ethanol leaf extract has reported for its anticonvulsant properties. SC used in traditional medicine to treat convulsion and epilepsy were studied in mice using pentylenetetrazole, picrotoxin, and electro-shock induced models in mice. On the basis of its biological activity, the plant might be responsible to treat diabetic neuropathy by an enhancement of GABA inhibitory action and/or inhibition of voltage-dependent sodium channels [43].

In the present study, STZ injected rats had significantly higher BSL level, which provokes diabetic neuropathy that was associated with the neuropathic pain. In addition, EFESC, attenuated STZ induced thermal hyperalgesia, mechanical hyperalgesia and tactile allodynia. 
The nociceptive threshold was significantly lowered in DC rats compared to NC rats in tail immersion and hot plate technique. This indicates that diabetic animals exhibited thermal hyperalgesia, post development of diabetic neuropathy. Consequently, hyperalgesia and neuropathic pain caused further decrease in pain threshold on exposure to thermal heat in tail immersion and hot plate method in uncontrolled diabetic rats (DC rats). Contrary to that, administration EFESC in diabetic rats not only reduced the BSL level but also lead to maximum improvement in pain threshold in a progressive manner in tail immersion and hot plate tests, indicating the better control of BSL, reduction in neuropathic pain and thermal hyperalgesia. However, SC is scientifically reported for its analgesic effect [44], which indicates its possible role in relieving the pain of diabetic neuropathy.

A strong relationship exists between glycemia and diabetic microvascular complications in both type 1 and type 2 diabetes [45]. Generation of superoxide due to oxidative stress in diabetes may be responsible for vascular and neuronal complications of painful neuropathy [26]. Early in the course of diabetes, intracellular hyperglycemia causes abnormalities in blood flow and increased vascular permeability.

Hyperglycemia affects the pro-oxidant state of the tissue. Oxidative stress and neuroinflammation combined with the decline in antioxidative defence potential have been documented as the key pathophysiological mechanism, involved in various complications including diabetic neuropathy [46]. Hyperglycemia is also caused due to increased polyol pathway activity, oxidative stress, advanced glycation end product formation, increased activation of protein kinase $C$, nerve hypoxia/ischemia and impaired NGF support [32] and all these pathways contribute to the development of diabetic neuropathy. One of the important consequences of chronic hyperglycemia is the enhanced oxidative stress resulting from an imbalance between the production and neutralization of reactive oxygen species (ROS). Clinical trials with aldose reductase inhibitor, Sorbinil (Pfizer-CP45634) have demonstrated significant improvement in the pain relief, motor and sensory nerve conduction velocities with minimum toxicity in patients with DN. These observations suggest that aldose reductase inhibitors may be important in the treatment of symptomatic, somatic and autonomic neuropathies complicating diabetes [47]. Hence the in vitro effect of EFESC on aldose reductase inhibition was studied. It showed an inhibitory effect although the $\mathrm{IC}_{50}$ was higher as compared to the standard (quercetin). Thus, the beneficial effect of SC on diabetic neuropathy appears to be due to its analgesic effect and unrelated to its anti-hyperglycemic effect. Aldose reductase inhibition may contribute to this action. An antioxidant role of SC cannot be ruled out as oxidative damage contributes to the causation of diabetic neuropathy and SC is proven to be an anti-oxidant in experimental models [48].

\section{CONCLUSION}

The data of the present study suggest a potential protective role of EFESC against STZ induced diabetes and diabetic neuropathy in rats. The onset of neuropathic complications could be prevented by early glycemic controls. These results further validate the traditional use of SC against diabetes and its complications. In future experiments involving nerve conduction studies would be more efficacious for the claim against diabetic neuropathy.

\section{ACKNOWLEDGEMENT}

Authors are thankful to BCUD Savitribai Phule Pune University for providing of research grant and Sapkal Knowledge Hub for providing research facilities. We are also thankful SES's R. C. Patel college of Pharmaceutical Education and Research, Shirpur for their kind support.

\section{AUTHORS CONTRIBUTIONS}

The experimental part of the work and writing of the manuscript was done by the first author Prof. Rishikesh Bachhav. The correction of the manuscript was done by the author Prof. Ravindranath Saudagar

\section{CONFLICT OF INTERESTS}

Declared none

\section{REFERENCES}

1. Edwin E, Sheeja E, Dhanabal S, Suresh B. Antihyperglycemic activity of Passiflora mollissima bailey. Indian J Pharm Sci 2007;69:570-1.

2. Kamenov ZA, Parapunova RA, Georgieva RT. Earlier development of diabetic neuropathy in men than in women with type 2 diabetes mellitus. Gend Med 2010;7:600-15.

3. Inukai T, Fujiwara Y, Tayama K, Aso Y, Takemura Y. Serum levels of carboxy-terminal propeptide of human type I procollagen are an indicator for the progression of diabetic nephropathy in patients with type 2 diabetes mellitus. Diabetes Res Clin Pract 2000;48:23-8.

4. Chait A, Bornfeldt KE. Diabetes and atherosclerosis: is there a role for hyperglycemia? J Lipid Res 2009;50 Suppl:S335-S9.

5. Romero Aroca P, Fernandez Balart J, Baget Bernaldiz M, Martinez Salcedo I, Mendez Marin I, Salvat Serra M, et al. Changes in the diabetic retinopathy epidemiology after $14 \mathrm{y}$ in a population of type 1 and 2 diabetic patients after the new diabetes mellitus diagnosis criteria and a more strict control of the patients. J Diabetes Complications 2009;23:229-38.

6. Dyck PJ, Kratz K, Karnes J, Litchy WJ, Klein R, Pach J, et al. The prevalence by staged severity of various types of diabetic neuropathy, retinopathy, and nephropathy in a populationbased cohort the rochester diabetic neuropathy study. Neurology 1993;43:817.

7. Yadav SK, Nagori BP, Desai PK. Pharmacological characterization of different fractions of Calotropis procera (Asclepiadaceae) in streptozotocin-induced experimental model of diabetic neuropathy. J Ethnopharmacol 2014;152:349-57.

8. Boulton A, Ward J. Diabetic neuropathies and pain. Clin Endocrinol Metabol 1986;15:917-31.

9. Pulipati S, Parveen SH, Babu RK. Pharmacognostical and physicochemical standardization of leaves of Spathodea campanulata P. Beauv J Pharmacogn Phytochem 2013;2:18992.

10. Trigo J, dos Santos W. Insect mortality in Spathodea campanulata Beauv. (Bignoniaceae) flowers. Rev Bras Biol 2000;60:537-8.

11. Liu J. Pharmacology of oleanolic acid and ursolic acid. J Ethnopharmacol 1995;49:57-68.

12. Kovoor A. Comparative effect of the intra-calicinal fluid of Spathodea campanulata Beauv. on the growth of plant tissue cultures. C R Hebd Seances Acad Sci 1953;237:832.

13. Houghton $P$, Hylands $P$, Mensah $A$, Hensel A, Deters A. In vitro tests and ethnopharmacological investigations: wound healing as an example. J Ethnopharmacol 2005;100:100-7.

14. Amusan 00, Adesogan EK, Makinde JM. Antimalarial active principles of Spathodea campanulata stem bark. Phytother Res 1996;10:692-3.

15. Niyonzima G, Laekeman G, Witvrouw M, Van Poel B, Pieters L, Paper D, et al. Hypoglycemic, anti-complement and anti-HIV activities of Spathodea campanulata stem bark. Phytomedicine 1999;6:45-9.

16. Ofori Kwakye K, Kwapong A, Adu F. Antimicrobial activity of extracts and topical products of the stem bark of Spathodea campanulata for wound healing. Afr J Tradit Complement Altern Med 2009;6:168-74.

17. Kowti R, Harsha R, Ahmed MG, Hareesh A, Gowda ST, Dinesha $\mathrm{R}$, et al. Antimicrobial activity of ethanol extract of leaf and flower of Spathodea campanulata P. Beauv. Res J Pharm Biol Chem Sci 2010;1:691-8.

18. Niyonzima G, Scharpe S, Van Beeck L, Vlietinck A, Laekeman G, Mets T. Hypoglycaemic activity of Spathodea campanulata stem bark decoction in mice. Phytother Res 1993;7:64-7.

19. Scogin R. Anthocyanin of bignoniacea. Biochem Syst Ecol 1980;8:273-6.

20. Ghosh D, Konishi T. Anthocyanins and anthocyanin-rich extracts: role in diabetes and eye function. Asia Pac J Clin Nutr 2007;16:200-8.

21. KR Khandelwal. Practical pharmacognosy techniques and experiments. $19^{\text {th }}$ ed. Nirali Prakashan Pune; 2007. p. 149-56. 
22. Harbone JB. Phytochemical methods: a guide to modern techniques of plant analysis. 5th Edn. Chapman and Hill, London; 2007. p. 279-83.

23. Wagner H, Bladt S, Zgainski EM. TLC screening of an unknown c ommercial drug. Germany: Springer-Verlag Berlin; 2001. p. 291- 305.

24. Frank B. Low dose streptozotocin induction protocol (Mouse). animal models of diabetic complication consortium. Available from: http://www.amdcc.org/. [Last accessed on 15 Apr 2014]

25. Nadig PD, Revankar RR, Dethe SM, Narayanswamy SB, Aliyar MA. Effect of Tinospora cordifolia on experimental diabetic neuropathy. Indian J Pharmacol 2012;44:580-3.

26. Anjaneyulu M, Chopra K. Quercetin attenuates thermal hyperalgesia and cold allodynia in STZ-induced diabetic rats. Indian J Exp Biol 2004;42:766-9.

27. Morani A, Bodhankar S. Neuroprotective effect of early treatment with Pioglitazone and pyridoxine hydrochloride in alloxan induced diabetes in rats. Pharmacologyonline 2007;2:418-28.

28. Adhikteari R, Jyothi Y, Bora D, Vamsee VA. Combined effect of aqueous extract of Curcuma longa Linn. with metformin in diabetes induced neuropathic pain in rats. Asian J Pharm Clin Res 2015;8:166-70.

29. Hayman S, Kinoshita JH. Isolation and properties of lens aldose reductase. J Biol Chem 1965;240:877-82.

30. Gul H, Yildiz 0, Dogrul A, Yesilyurt 0, Isimer A. The interaction between IL-1 $\beta$ and morphine: possible mechanism of the deficiency of morphine-induced analgesia in diabetic mice. Pain 2000;89:39-45.

31. Calcutt NA, Chaplan SR. Spinal pharmacology of tactile allodynia in diabetic rats. Br J Phamacol 1997;122:1478-82.

32. Pop-Busui R, Sima A, Stevens M. Diabetic neuropathy and oxidative stress. Diabetes/Metab Res Rev 2006;22:257-73.

33. Hoybergs YM, Biermans RL, Meert TF. The impact of bodyweight and body condition on behavioral testing for painful diabetic neuropathy in the streptozotocin rat model. Neurosci Lett 2008;436:13-8.

34. Ilnytska 0, Lyzogubov VV, Stevens MI, Drel VR, Mashtalir N, Pacher $\mathrm{P}$, et al. Poly (ADP-ribose) polymerase inhibition alleviates experimental diabetic sensory neuropathy. Diabetes 2006;55:1686-94
35. Serra J, Sola R, Quiles C, Casanova Molla J, Pascual V, Bostock H et al. C-nociceptors sensitized to cold in a patient with smallfiber neuropathy and cold allodynia. PAIN 2009;147:46-53.

36. Fruhstorfer $H$. Thermal sensibility changes during ischemic nerve block. Pain 1984;20:355-61.

37. Yarnitsky D, Ochoa JL. Release of cold-induced burning pain by block of cold-specific afferent input. Brain 1990;113:893-902.

38. Ochoa JL, Yarnitsky D. The triple cold syndrome. Brain 1994;117:185-97.

39. Campero M, Baumann T, Bostock H, Ochoa J. Human cutaneous $\mathrm{C}$ fibres activated by cooling, heating and menthol. J Physiol 2009;587:5633-52.

40. Ngouela S, Tsamo E, Sondengam BL. Extractives from bignoniaceae: constituents of the stem bark of Spathodea campanulata. Planta Med 1988;54:476-85.

41. Kumaresan M, Palanisamy P, Kumar P. Chemical investigation of flower of Spathodea campanulata by GC-MS. J Nat Prod Plant Resour 2011;1:14-7.

42. Baluchnejadmojarad T, Roghani M, Khastehkhodaie Z. Chronic treatment of silymarin improves hyperalgesia and motor nerve conduction velocity in diabetic neuropathic rat. Phytother Res 2010;24:1120-5.

43. Ilodigwe EE, Akah PA, Nworu CS. Anticonvulsant activity of ethanol leaf extract of Spathodea campanulata P. Beauv (Bignoniaceae). J Med Food 2010;13:827-33.

44. Ilodigwe EE, Akah PA. Spathodea campanulata: an experimental evaluation of the analgesic and anti-inflammatory properties of a traditional remedy. Asian J Med Sci 2009;1:235-8.

45. Brownlee M. Biochemistry and molecular cell biology of diabetic complications. Nature 2001;414:813-20.

46. Gupta NK, Shrivastav N, Puri S, Bubber P, Puri V. Neuroprotective potential of Azadirachta indica leaves in diabetic rats. Asian J Pharm Clin Res 2017;10:243-8.

47. Jaspan J, Herold K, Maselli R, Bartkus C. Treatment of severely painful diabetic neuropathy with an aldose reductase inhibitor: relief of pain and improved somatic and autonomic nerve function. J Lance 1983;322:758-62.

48. Akharaiyi F, Boboye B, Adetuyi F. Antibacterial, phytochemical and antioxidant activities of the leaf extracts of Gliricidia sepium and Spathodea campanulata. World Appl Sci 2012;16:523-30. 